\title{
Mees' Lines
}

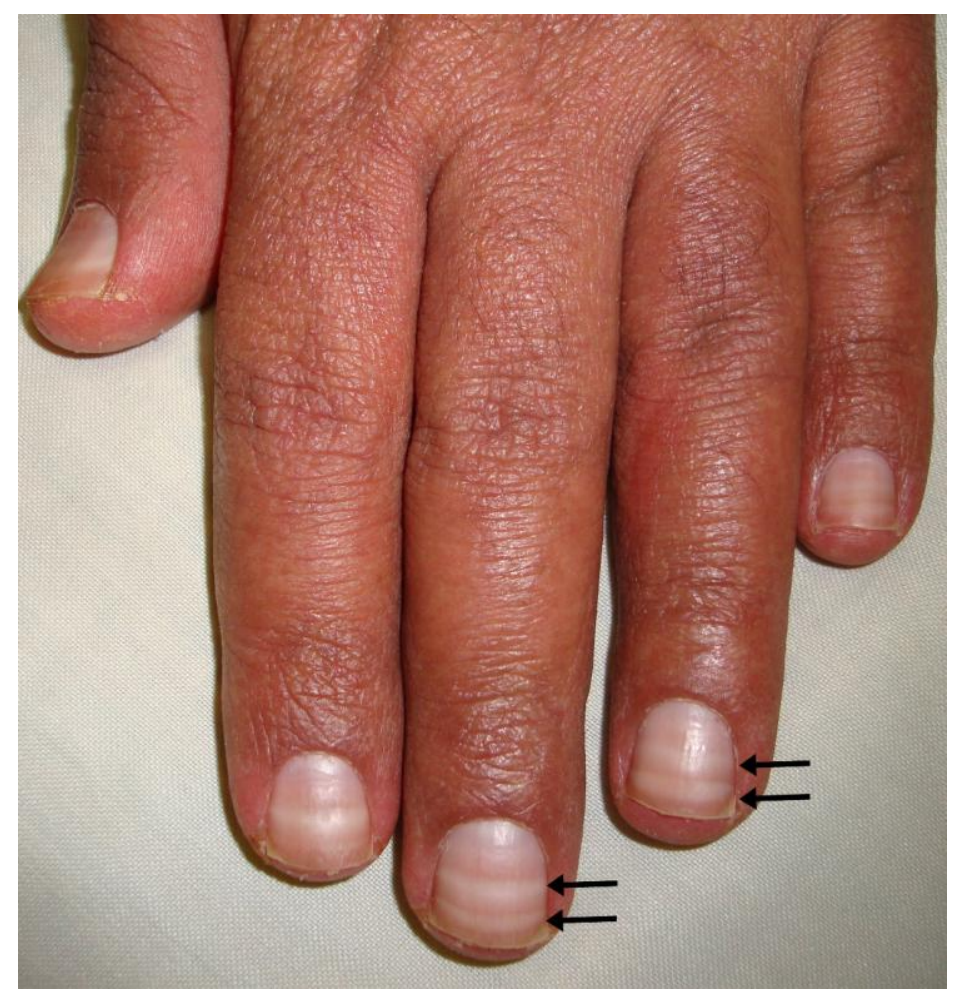

FIGURE 1. Mees' lines: white, nonblanching, transverse bands running parallel to the lunula.

\author{
Hadi Mirfazaelian ${ }^{1, \star}$, Mohammad Reza Namazi ${ }^{2}$, \\ and Yahya Daneshbod ${ }^{3}$ \\ ${ }^{1}$ Department of Emergency Medicine, Tehran University of Medical Sciences, \\ Tehran, Iran; ${ }^{2}$ Shiraz Skin Research Center, Shiraz University of Medical Sciences, \\ Shiraz, Iran; ${ }^{3}$ Department of Pathology, Dr. Daneshbod Laboratory, Shiraz Iran \\ E-mail: Hadimir 43@yahoo.com; namazi mr@yahoo.com; y@daneshbod.com; daneshbk@yahoo.com
}

Received November 16, 2010; Revised December 22, 2010; Accepted December 23, 2010; Published February 3,2011

KEYWORDS: Mees' lines, chemotherapy 
A 28-year-old man, a known case of acute myelogenous leukemia (AML) (M4), was admitted because of cutaneous infection and pancytopenia 1 month after his second chemotherapy cycle, with no data available about the chemotherapy regimen. On physical examination, in addition to scaling and desquamation on some of his fingers, there were some changes in his nails that started after his first chemotherapy cycle. There were white, nonblanching, transverse bands running parallel to the lunula across the entire nail bed with no palpable ridges (Fig. 1, arrows). These lines, known as Mees' lines (true leukonychia) are related to each chemotherapy cycle, with the distance between them pertaining to the cycles' intervals[1]. Although the patient did not recall the time of the appearance of the lines, knowing that nails grow about $1 \mathrm{~mm}$ every 6 to 10 days, the timing of the disease process may be estimated by measuring the distance from the line to the nail bed[2]. They are caused by an insult to the distal nail matrix, which unlike Beau's lines, do not interrupt growth of the matrix, but causes parakeratosis of the ventral nail plate[3]. Mees' lines can be differentiated from Muehrcke's lines (apparent leukonychia), which are paired white lines caused by vascular congestion in the nail bed, by not fading after digital compression and migration with the growth of the nail in Mees' lines[3]. In addition, thumb involvement is rare in Muehrcke's lines[4]. Differential diagnosis of Mees' lines are arsenic poisoning, Hodgkin's disease, congestive heart failure, leprosy, malaria, chemotherapy, carbon monoxide poisoning, and other systemic insults[2]. Four months later, the patient underwent bone marrow transplantation, but unfortunately died because of sepsis.

\section{REFERENCES}

1. Park, J. and Li, K. (2010) Images in clinical medicine. Multiple Beau's lines. N. Engl. J. Med. 362(20), e63.

2. Fawcett, R.S., Linford, S., and Stulberg, D.L. (2004) Nail abnormalities: clues to systemic disease. Am. Fam. Physician 69(6), 1417-1424.

3. Huang, T.C. and Chao, T.Y. (2010) Mees lines and Beau lines after chemotherapy. CMAJ 182(3), E149.

4. Morrison-Bryant, M. and Gradon, J.D. (2007) Images in clinical medicine. Muehrcke's lines. N. Engl. J. Med. 357(9), 917. 


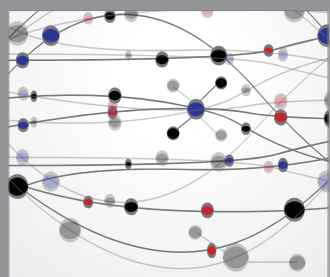

The Scientific World Journal
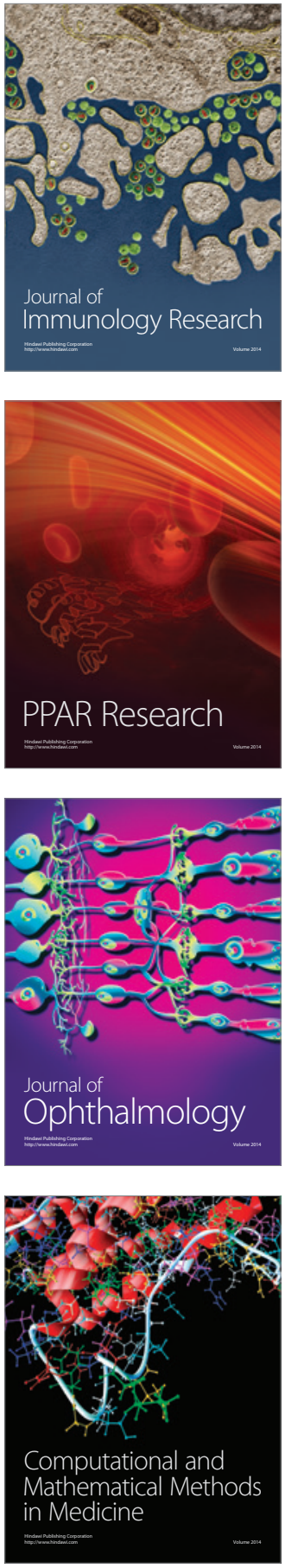

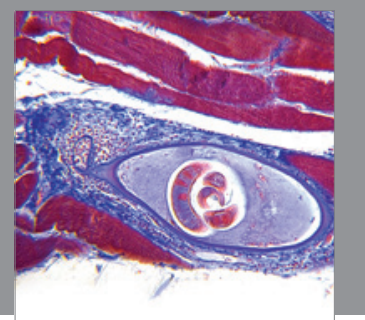

Gastroenterology

Research and Practice
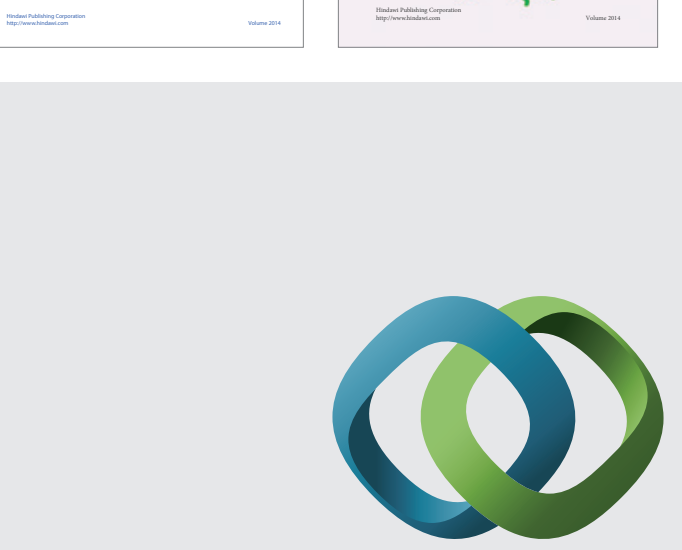

\section{Hindawi}

Submit your manuscripts at

http://www.hindawi.com
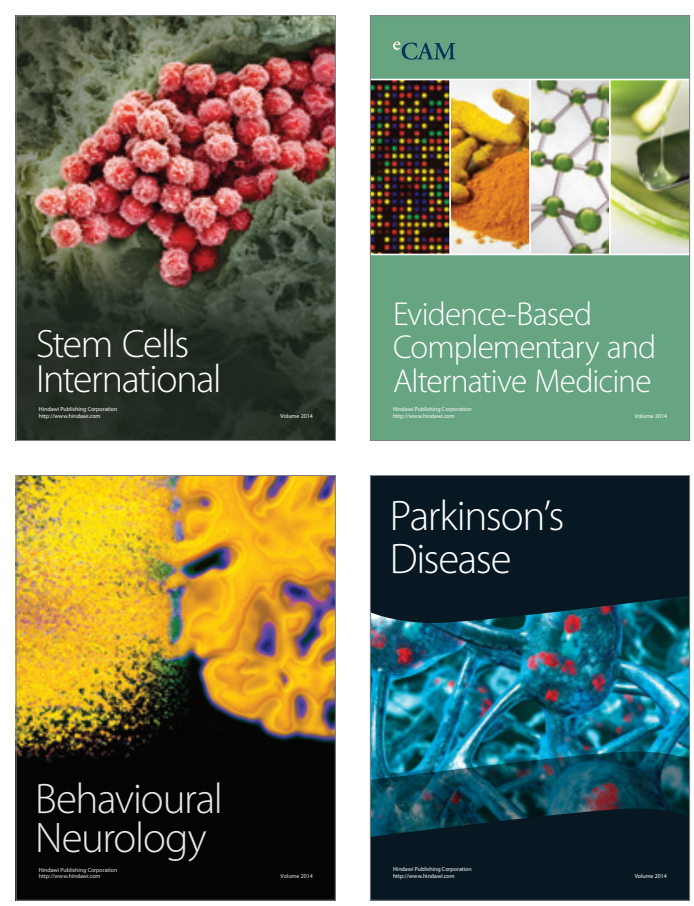

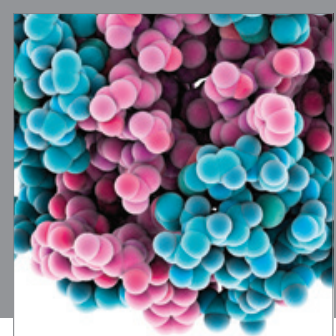

Journal of
Diabetes Research

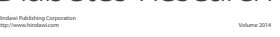

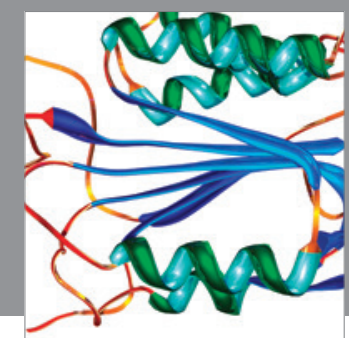

Disease Markers
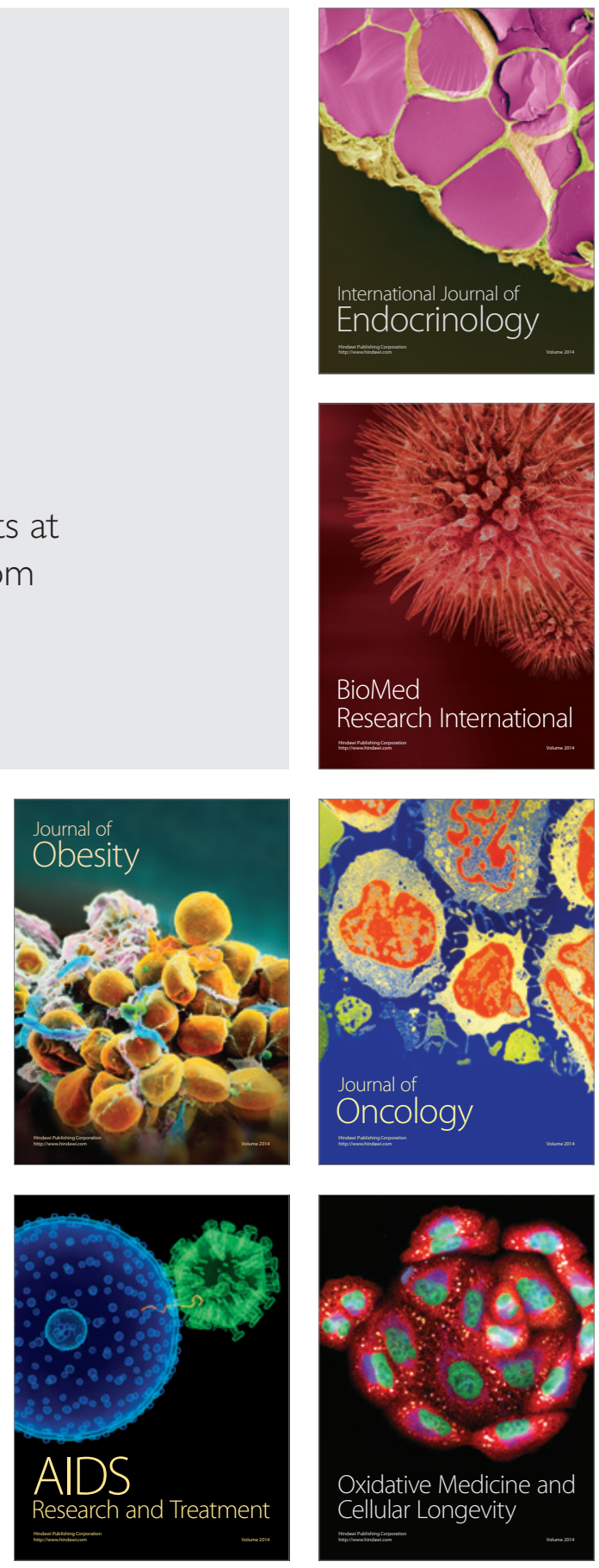